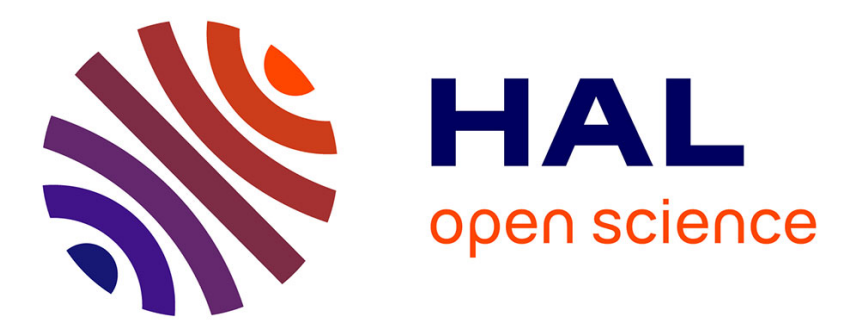

\title{
Analysis of Ovalization Measurements on Flexible Airfield Pavement under HWD Dynamic Impulse Load
}

Maïssa Gharbi, Michaël Broutin, Ichem Boulkhemair, Mai Lan Nguyen, Armelle Chabot

\section{- To cite this version:}

Maïssa Gharbi, Michaël Broutin, Ichem Boulkhemair, Mai Lan Nguyen, Armelle Chabot. Analysis of Ovalization Measurements on Flexible Airfield Pavement under HWD Dynamic Impulse Load. RILEM International Symposium on Bituminous Materials (ISBM), Dec 2020, Lyon, France. pp.263-269 in RILEM Bookseries, vol. 27, 2022, 10.1007/978-3-030-46455-4_33 . hal-03012823

\section{HAL Id: hal-03012823 https://hal.science/hal-03012823}

Submitted on 18 Nov 2020

HAL is a multi-disciplinary open access archive for the deposit and dissemination of scientific research documents, whether they are published or not. The documents may come from teaching and research institutions in France or abroad, or from public or private research centers.
L'archive ouverte pluridisciplinaire HAL, est destinée au dépôt et à la diffusion de documents scientifiques de niveau recherche, publiés ou non, émanant des établissements d'enseignement et de recherche français ou étrangers, des laboratoires publics ou privés.

$$
\text { Copyright }
$$




\title{
Analysis of Ovalization Measurements on Flexible Airfield Pavement under HWD Dynamic Impulse Load
}

\author{
Maissa Gharbi ${ }^{1[0000-0002-5720-9943]} *$, Michael Broutin ${ }^{1[[0000-0002-8446-8019]}$, Ichem \\ Boulkhemair ${ }^{1 \mid[0000-0001-7795-1080]}$, Mai. Lan Nguyen ${ }^{2[0000-0001-8966-5209]}$, Armelle Cha- \\ bot $^{2[0000-0002-9430-8457]}$ \\ ${ }^{1}$ French Civil Aviation Technical Center (STAC), Bonneuil-sur-Marne, France \\ ${ }^{2}$ MAST-LAMES, Univ Gustave Eiffel, IFSTTAR, F-44344 Bouguenais, France \\ *maissa.gharbieregis-dgac.net
}

\begin{abstract}
Non-destructive techniques (NDT) have emerged for the last decades to in-situ evaluate the pavement materials and interface conditions. These techniques turn out to be valuable tools to evaluate pavement bearing capacity, but present limitations to provide, on their own, reliable information about the interface bonding conditions. Developed in the 70 's, the ovalization test aims at evaluating the interface bonding condition between pavement layers over the cross of a rolling wheel loads. It consists in measuring the diameter variation of a cavity at different depth levels and in three horizontal directions (longitudinal, transverse and at $45^{\circ}$ related to the loading direction). The French civil Aviation technical center (STAC) launched a research project to evaluate this device for flexible airfield pavement submitted to dynamic loadings. This paper presents some of the first multi-height tests that have been performed using the Heavy Weight Deflectometer (HWD) impulse loading at the STAC's full-scale airfield pavement test facility constructed on the Centre d'Expérimentations Routière (CER) site at Rouen in France. The results lead to propose the design of new ovalization devices for airfield pavements.
\end{abstract}

Keywords: Ovalization test, HWD, Airfield pavement, Interfaces, Modeling.

\section{Introduction}

Diagnosis step is of major concern in the frame of any study about in-service pavement. It allows assessing the pavement condition, identifying distresses, evaluating a residual life and/or anticipating potential maintenance. The interface bonding conditions between bituminous layers are a particular area of focus [1]. Non-destructive techniques (NDT), such as the Heavy Weight Deflectometer (HWD) used for airfield pavements $[2,3]$, have emerged for the last decades to in-situ evaluate the pavement

This paper presented at RILEM ISBM Lyon 2020 is accepted for publication in the RILEM Bookseries Vol. 27, that it is copyrighted by RILEM @2021. Readers must contact RILEM for permission to reprint or use the material in any form. The original publication is available at web site of the Springer International Publishing's: https://www.springer.com/gp/book/9783030464547 
materials and the interface conditions [4]. These techniques turn out to be valuable tools to evaluate pavement bearing capacity, but present limitations to provide, on their own, reliable information about interfaces conditions. One of the common options is to implement strain gauges at the bottom of pavement layers during the pavement construction. However, this method is costly and delicate.

Developed in the 70's from the regional laboratory of Saint Brieuc [5, 6, 7], the ovalization test aims at evaluating interface bond condition between pavement layers over the cross of rolling wheel loads. It consists in measuring the diameter variation of a cavity at different depth levels and in three horizontal directions (longitudinal (L), transverse (T) and $45^{\circ}$ related to the loading direction). The French civil Aviation technical center (STAC) launched a research project to evaluate this test for flexible airfield pavement submitted to dynamic loadings. Its objective is to evaluate existing devices and to modernize or eventually to propose new systems for airfield flexible pavement interface characterization needs. The ovalization system has to enable:

-simultaneous multi-depth measurements at different levels within the bituminous surface course, including the pavement surface level;

-interface characterization linked to both rolling wheel loading and HWD stationary impulse loading at several distances from cavity including the possibility to position the HWD test plate centered right above the cavity (axisymmetric configuration).

This paper describes first the ovalization test principle and some test responses obtained on a full-scale section that have been loaded by HWD during autumn 2018.

\section{History of the Ovalization Test}

As indicated in the literature $[5,8]$, the variation of the diameter of a cylindrical cavity (in three directions) linked to a surface loading, provides valuable information about stresses and strains inside the structure (Fig. 1a). In the case of a multi-layer structure, measuring such diameter variation below and above the interface between two layers allows assessing its bonding condition. Based on this concept, the ovalization test was firstly proposed in 1974 with a simple configuration named: the unidirectional sensor and used under rolling loads [5].
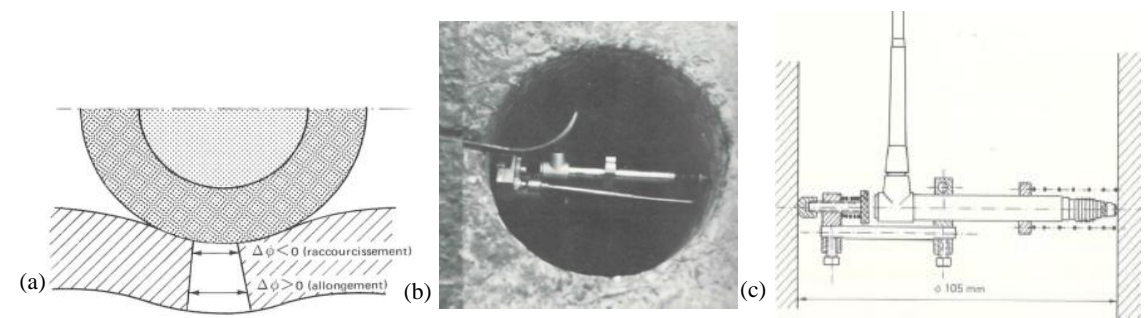

Fig. 1 The Ovalisation principle [5]: a) Diameter variation of the cylindrical cavity under loading; $b$ and c)The unidirectional sensor

It is composed of one electromagnetic sensor mounted on a bracket which ensures its holding to a set position in the hole and the setting of its measurement range (Fig. 1b, 1c). This unidirectional measurement system was improved and replaced with a 
tridirectional system (Fig. 2a) [6,9]. This first generation version, developed in 1983 [3] contains three electronic sensors which measure simultaneously the hole diameter variation in three plane directions ( $\mathrm{L}, \mathrm{T}$ and $45^{\circ}$ relatively to the loading direction) (Fig. 2b).
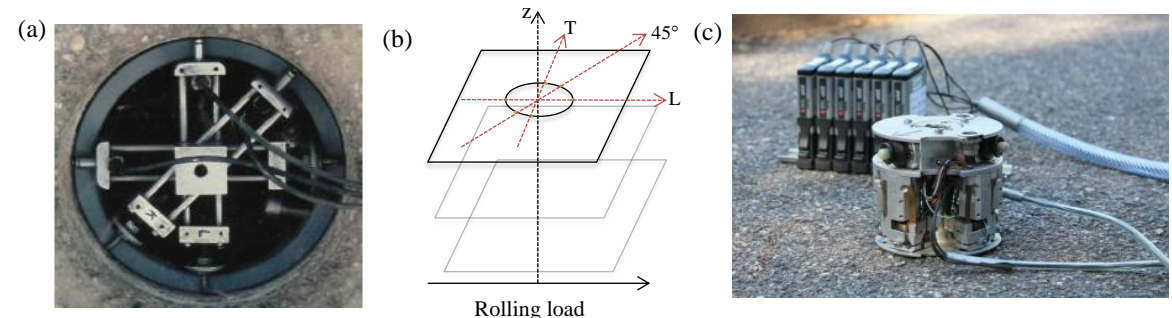

Fig. 2 Ovalization devices: a) The ovalization tridirectional first generation [3], b) The 3 plane direction; c) The CEREMA device [7]

As the setting-up of this tridimensional system (Fig. 2a) was very tedious and sensitive, the Centre d'étude et d'expertise sur les risques, l'environnement, la mobilité et l'aménagement (CEREMA) upgraded it. It leads to the 2nd generation tridirectional probe (Fig. 2c). This new device includes a six sensors system (two per direction) and involves electric motors for automated positioning. Like the aforementioned unidirectional and first generation tri-directional probe, this second generation tri-directional probe enables measuring the cavity diameter variations at only one depth at a time.

\section{Ovalization Campaigns for Airfield Pavement Needs}

In the aim to evaluate the second generation of the tridirectional probe [7] for airfield pavement, the device has been tested under both rolling wheel loading and HWD impulse loading. Tests were conducted in 2018 with this system, designed for 107 mm cavity diameter, in partnership with the CEREMA, at the STAC's full-scale airfield pavement test facility constructed on the Centre d'Expérimentations Routières (CER) site (Rouen, France). The pavement structure is a conventional airfield flexible pavement composed of a bituminous surface course and a humidified UGA subbase layer (Fig. 3). It comprises two areas, singled out by the subgrade water-content. The ovalization test campaign was performed in the area presenting a water-saturated subgrade. The average temperature within the bituminous layer was constant during the whole test campaign, equal to $7^{\circ} \mathrm{C}$. The maximal acquisition frequency reached during this test campaign was $\sim 130 \mathrm{~Hz}$. 


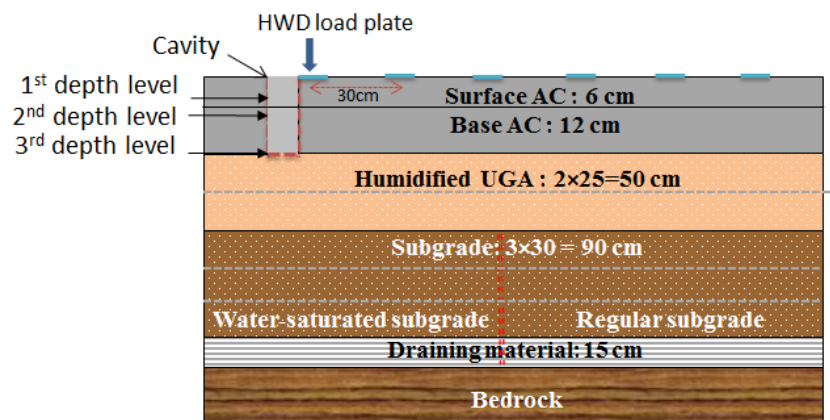

Fig. 3 STAC's full scale facility and HWD vs ovalization experimental protocol

Fig. 4a illustrates an example of the diameter variation curves measured in the three directions ( $\mathrm{T}, \mathrm{L}$ and $45^{\circ}$ ) under rolling loading condition, at an unidentified level within the bituminous course, some doubts existing about the tests referencing. A regular shape without significant defect is observed. It shows that the $\sim 130 \mathrm{HZ}$ acquisition frequency is high enough for those loading conditions. It can then be concluded that the current ovalization system seems to be satisfactory for tests performed under rolling loading and with a $130 \mathrm{~Hz}$ acquisition frequency.
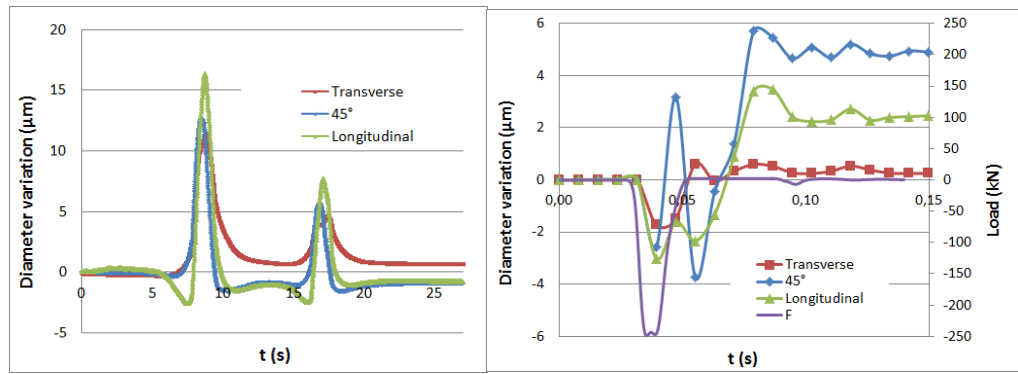

Fig. 4 CEREMA ovalization device measurements: a) cavity diameter variations under rolling loading b) cavity diameter variations under HWD at the bottom of the cavity

In a second part, the experimental program includes HWD tests at six different distances from the cavity (Fig. 3). In the cavity, the ovalization system is placed one at a time at three depths within the bituminous layer. Two HWD load levels (respective peak values $\mathrm{F}_{1} \sim 250 \mathrm{kN}$ and $\mathrm{F}_{2} \sim 125 \mathrm{kN}$ ) were applied. For each HWD test and for each load level, three drops were performed for repeatability study. Despite the important number of tests that have been carried out under the HWD loading in this experimental program, only a very few tests are exploitable. The Fig. $4 \mathrm{~b}$ presents one example of the diameter variation curves measured in the three directions at the bottom of the cavity, corresponding to a test performed at $60 \mathrm{~cm}$ from the cavity. An oscillation shape is observed for all curves which derives from mechanical vibrations of the probe. Furthermore, the acquisition frequency $(\sim 130 \mathrm{~Hz})$ which is the maximal rate applicable for this prototype is not satisfying. Those experimental findings are 
then not reliable enough and cannot be used for comparison with FE modeling work. New devices are proposed.

\section{New Design Proposals for the Ovalization Device}

For tests performed under HWD load, due to such dynamic load, previously mentioned results show some limitations of the current system of the ovalization test. Actually it is not possible to reach an adequate acquisition frequency for such a dynamic load. The measurements involving HWD tests require appropriate acquisition rates, at least $300 \mathrm{~Hz}$ and preferably $1 \mathrm{kHz}$. Furthermore it does not allow the measurement of the diameter variation at the surface of the surface AC layer, and the implementation of centered HWD tests calls for wireless system. To achieve these requirements, two prototypes were recently developed by the STAC (Fig. 5).

(a)

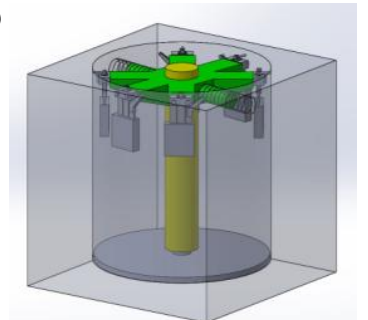

(b)

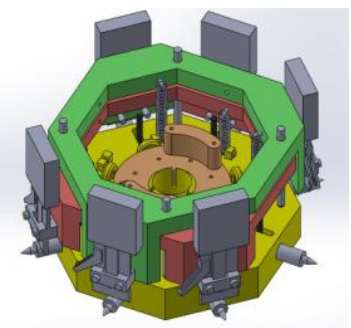

Fig. 5 STAC's Ovalization prototype: a) First Design, b) Second Design

It consists in self-bearing horizontal tray equipped, with six DD1 sensors (provided by HBM constructor) positioned in pairs for each direction ( $\mathrm{L}, \mathrm{T}, 45^{\circ}$ ). It makes possible to assess the diameter variation. Each system can easily be upgraded to a multiple tray system for simultaneous multi-depth measurements. Measurements at the surface of the bituminous course layer are possible. The mechanical and electronical systems retained are consistent with measurements under HWD dynamic impulse loads. Particularly, it enables reaching acquisition rates compatible with those solicitations.

Tests were conducted at the STAC full-scale airfield pavement test facility in Bonneuil-sur-Marne [10, 2]. The Fig.6 shows first results of the ovalization test performed with the two news prototypes successively placed within the cavity at the pavement surface under HWD impulse loading. Tests are firstly carried out with the HWD plate positioned adjacent to the cavity edge with a HWD load peak value of F $170 \mathrm{kN}$ and with an adequate frequency acquisition $(4800 \mathrm{~Hz})$. Others load peak values were applied and the results are presented in [10]. For the second prototype (Fig. 6b) an oscillation shape is observed for the diameter variations curves contrary to first prototype (Fig. 6a) which seems to be more satisfactory.

The improvement of both prototypes is in progress to overcome some limitations related to the implementation step and to the curve oscillation issue. 


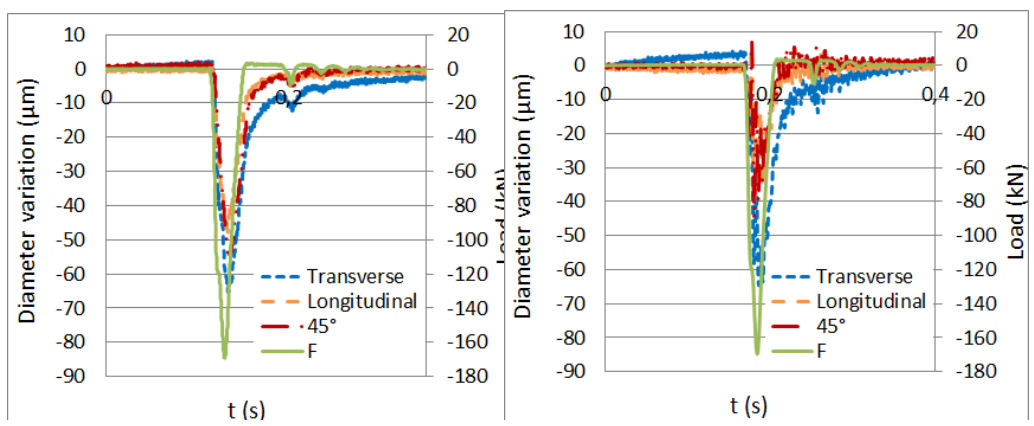

Fig. 6 Diameter variations curves at the surface of the cavity using: a) the First Design, b) Second Design

\section{Conclusion}

This paper presents some results from two ovalization test campaigns carried out at the STAC's full-scale airfield pavement test facility, on the CER site in 2018. The CEREMA second generation probe of Ovalization device is evaluated for airfield pavement needs. These test campaigns include both conventional tests using rolling wheel load, and new type of loading involving Heavy Weight Deflectometer (HWD) impulse load, performed at different distances from the cavity. Those tests where. The cavity diameter variation is studied in three horizontal directions $\left(\mathrm{T}, \mathrm{L}\right.$ and at $\left.45^{\circ}\right)$ for both loading conditions. The conventional tests showed satisfactory results. By contrast, measurements obtained under HWD impulse load are not exploitable: the acquisition rate is too low for such solicitation and mechanical vibrations are observed. Furthermore, the current system does not enable performing diameter measurements at the pavement surface, neither carrying out HWD tests with the load plate centered right above the cavity (axisymmetric configuration). In order to overcome these current system limitations, two new ovalization systems are being developed by the authors [10] and first tests are briefly presented here. In parallel, 3D finite element dynamic modeling is developed for data analysis, more tests and results will be illustrated in [10].

\section{References}

[1] Petit, C., Chabot, A., Destrée, A., Raab, C.: Interface debonding behaviour. In: Buttlar, WG., Chabot, A., Dave, ED., Petit, C., Tebaldi, G. (eds.) MCD in Asphalt and Composite Pavements. RILEM State-of-the-Art Reports Vol 28, pp. 103-153. 1rs eds. Springer, Cham (2018). doi: 10.1007/978-3-319-76849-6_3

[2] Broutin, M., Sadoun, A., Duprey, A.: Comparison between HWD Backcalculated Subgrade Dynamic Moduli and In Situ Static Bearing Capacity Tests. In: Al-Qadi, I., Ozer, H., Loizos, A., Murrell, S. (eds.), AHP2019, pp. 404-413. ASCE Press (2019).

[3] STAC: Airfield flexible pavement assessment using HWD. Guide Technique (2014). 
[4] Sadoun, A., Broutin, M., Simonin, JM.: Assessment of HWD Ability to Detect Debonding of Pavement Layer Interfaces. In: Chabot, A., Buttlar, WG., Dave, EV., Petit, C., Tebaldi, G. (eds.), Rilem Bookseries, Vol.13 pp. 763-769. Springer Netherlands, Dordrecht, (2016).

[5] Kobisch, R., Peyronne, C. : L'ovalisation : une nouvelle méthode de mesure des déformations élastiques des chaussées, Bull. Liaison Labo P. et Ch. (102), 59-71. (1979).

[6] Goacolou, H., Keryell, P., Kobisch, R., Poilane, JP. : Utilisation de l'ovalisation en auscultation des chaussées. Bull. Liaison Labo P. et Ch. (128), 65-75 (1983).

[7] Ruiz, O., Voisin, G.: L'essai d'ovalisation, RGRA (962), (2019).

[8] Savin, G. N.: Stress Concentration Around Holes. 1rs eds. Pergamon (1961).

[9] Martin, JM. : Ovalisation, exécution et exploitation des mesures : méthode d'essai LPC $\mathrm{n}^{\circ}$ 41. Laboratoire Central des Ponts et Chaussées (1995).

[10] Gharbi, M., Broutin, M., Schneider, T., Maindroult, S., Chabot, A.: Towards an adapted ovalization system for flexible airfield pavement interface characterization using rollingwheel or HWD loads. In: Chabot A., Hornych P., Harvey J., Loria-Salazar L. (eds), LNCE, vol. 96, pp. 516-525. Springer, Cham. https://doi.org/10.1007/978-3-030-552367_53. 